\title{
What is an Internship Report? Contributions to the Construction of its Meaning
}

\section{(iD) Ana Isabel Santos ${ }^{1}$ \\ D Carlos Miguel Ferreira ${ }^{2}$ \\ Sandro Serpa ${ }^{3}$ \\ (D) Maria Jose $\mathbf{S a}^{4}$}

${ }^{\prime}$ University of the Azores, Faculty of Social Sciences and Humanities, Department of Education; and Interdisciplinary Centre for Childhood and Adolescence - NICA-UAc, R. da Mãe de Deus, Ponta Delgada, The Azores, Portugal.

Email:ana.is.santos@uac.ptTel:351962860810

${ }^{2}$ ISCTE - University Institute of Lisbon, Av. das Forças Armadas, Lisbon, Portugal; Interdisciplinary Centre of Social Sciences - CICS; Estoril Higher Institute for Tourism and Hotel Studiesm Portugal.

Email:carlos.miguel.ferreira@iscte-iul.ptTel:938470163

${ }^{3}$ University of The Azores, Faculty of Social and Human Sciences, Department of Sociology; Interdisciplinary Centre of Social Sciences - CICS.UAc/CICS.NOVA.UAc; Interdisciplinary Centre for Childhood and Adolescence - NICA-UAcm, Portugal.

Email:sandro.nf.serpa@uac.ptTel:351964424554

${ }^{\text {} C I P E S-C e n t r e ~ f o r ~ R e s e a r c h ~ i n ~ H i g h e r ~ E d u c a t i o n ~ P o l i c i e s, ~ M a t o s i n h o s, ~ P o r t u g a l . ~}$

Email:mjsa@cipes.up.ptTel:351229398790

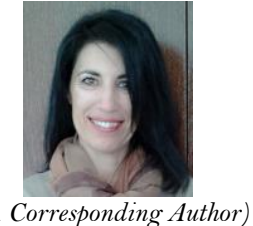

( Corresponding Author)

\section{Abstract}

The internship report is one of the prime elements to train and assess the student, usually in the final stage of a study cycle; it consists of placing the student in a context that is similar to a professional situation. This is a work of description and theoretical reflection, methodologically oriented towards the activities developed in the context of an internship in organisations. It is necessary to distinguish the internship report from an undergraduate thesis or dissertation that focuses mainly on the formal investigation component. However, even while respecting the specific features of each training context, as well as each scientific area, there are various interpretations of what an internship report is/should be, both in terms of its form and content. The internship report may be viewed as a theoretical and methodologically oriented work of description and reflection on the activities carried out within the scope of an internship in organisations. This critical essay seeks to provide insights into the process of developing an internship report.

Keywords: Internship report, Assessment, Supervised internship, Training, Theses, Dissertations.

Citation | Ana Isabel Santos; Carlos Miguel Ferreira; Sandro Serpa; Maria Jose Sa (2020). What is an Internship Report? Contributions to the Construction of its Meaning. Journal of Education and eLearning Research, 7(1): 1-6.

History:

Received: 2 October 2019

Accepted: 10 December 2019

Published: 13 January 2020

Licensed: This work is licensed under a Creative Commons

Attribution 3.0 License (cc)

Publisher: Asian Online Journal Publishing Group
Acknowledgement: All authors contributed to the conception and design of the study.

Funding: This study received no specific financial support

Competing Interests: The authors declare that they have no conflict of interests.

interests.
Transparency: The authors confirm that the manuscript is an honest, Transparency: The authors confirm that the manuscript is an honest,
accurate, and transparent account of the study was reported; that no vital features of the study have been omitted; and that any discrepancies from the study as planned have been explained.

Ethical: This study follows all ethical practices during writing.

\section{Contents}

1. Introduction

2. Methodology

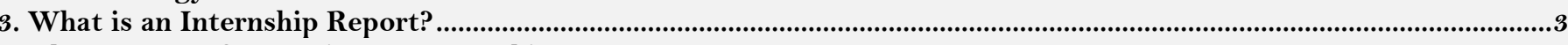

4. The Process of Preparing an Internship Report.

5. Conclusions

References..... 


\section{Contribution of this paper to the literature}

The internship report is a key element in many study programs in a variety of scientific fields. However, it is often only implied what an internship report should be, both for mentors and trainees themselves, which tends to shape different views on this important pedagogical and assessment tool. This paper seeks to offer a contribution at two levels. At the theoretical level, it seeks to add to the discussion, in the literature, on what should be an internship report focusing on its goals, respecting the various scientific areas. At the practical level, it intends to offer insights on the process of producing an internship report.

\section{Introduction}

The internship is a preponderant element in the training in numerous study programmes (Andrade and Mesquita, 2016) in the search to establish dialogues between its theoretical component and the professional performance of the student in training. Thus, the internship is a suitable space for the emergence of stressful situations of and in the learning that are expected to be capitalised in training and reflection, either in the context of the pre-teaching profession (Parveen and Mirza, 2012; Braga, 2015) or in other training contexts of approach to the professional practice (Gomes and Santana, 2019; Lopes et al., 2019). According to Braga (2015) "The internship is an articulating activity of the study programme and should favour a creative and transformative practice" (p. 255). Furthermore, Tiessen (2018) argues that "the quality of this learning can be limiting and superficial without proper facilitation and reflection. A praxis-oriented approach is essential to the learning cycle of any educational experience" (p. 8).

In this process of student development through the internship (Badger, 2012; Lima et al., 2018) the mentors or supervisors play a very important role through their feedback recommendations. For example, regarding internships in the training of future teachers, Badger (2012) reveals the need to provide in-depth and clear feedback to students:

"My investigation highlighted the need for mentors to consider in their assessment of student teacher's instruction questions related to the what, how, and why of instruction. Further, mentors should integrate in their feedback some of the salient issues and themes from university methods courses to foster integrative, self-reflective thinking in beginning teachers" (p. 35).

In these situations of internship, the internship report is one of the key elements to assess the student. This assessment usually takes place at the final stage of the training in a study cycle, regarding the student's performance in a context that is similar to a professional situation and it may be a process and, if well explored, it may be a product that fosters this reflective feedback. This element of student assessment that should be a reflection of their performance is based - on a logic of reflection and justification of the actions undertaken - in a critical perspective regarding their performance and the results of those actions. In this sense, the internship report may be viewed as a theoretical and methodologically oriented work of description and reflection on the activities carried out within the scope of an internship in organisations. In the specific case of the educational context, Silva (2012) sustains that "Synthetically, we understand the critical teacher as the professional who is used to reflecting on the characteristic dynamics of the workspace, and, depending on the reflections or assessments performed, (re)plan the guiding or organising activities of the pedagogical work carried out. These results reveal, therefore, the need for greater guidance of the writing practices by the supervisor of the supervised internship" (p. 302).

A specific difficulty emerges in the elaboration of the internship reports with the existence of several predicted models that may vary to a greater or lesser extent depending on the institutional factors, the training itself, the (in)competences and traits of the trainee and also of the advisor him/herself (Silva, 2013; Braga, 2015; Mendes et al., 2015).

However, there is a need to differentiate it from an end-of-study programme thesis, which focuses more on the component of formal research. Even respecting the contingency features of each training context, as well as each scientific area, there are many frequently different interpretations of what an internship report is/should be, both in terms of its form and content. This article offers insights on what an internship report should be in these two dimensions, as an element that can be a key enhancer, if well explored, of the student training (Andrade and Martins, 2017).

Numerous studies address the internship topic, focusing mainly on specific institutional contexts (school or otherwise) (Gabassa et al., 2017) virtual or otherwise (Mattos and Santos, 2018). Internships may take on distinct features in different contexts and depending on the trainees' standpoint, the trainees' relationship with the mentors and internship advantages and drawbacks.

Besides the internship process, the final product or result, usually in the written form of an internship report, seems to us worthy of further analysis that goes beyond the various casuistic normative formulations, but which may vary greatly (Ellis and Childs, 2019) either from one institution to another (Nisly et al., 2018) or in the area of scientific training and in the trainees', mentors' and host institutions' standpoint. Furthermore, it should be taken into account that "The issue of influence of mentoring style to the development of mentees' pedagogical and didactic competencies is still not sufficiently investigated" (Ciučiulkienè and Mičiuliené, 2019) and that "Mentoring is a process when a more qualified and experienced person teaches, supports, promotes, advises" (p. 131).

Thus, this article seeks to add to an analysis of the general framework in which supervised internships take place that may substantiate certain principles of universal generic implementation.

In summary, this reflection focuses on what is intended as a product, but also on its progressive development process that makes it the/an internship report, which may have very distinct meanings to different actors and/or training contexts (Silva, 2012;2013). Furthermore, it seeks to offer a comprehensive overview, based on literature but also on the authors' experience as internship supervisors, of what a quality internship report should be and how to reach this level of quality. 


\section{Methodology}

This study was carried out using the qualitative research methodology and document analysis was the chosen method. Thus, to meet the study goal, a document collection and analysis was carried out using the B-ON database (Online Knowledge Library, 2019) which provides articles from some of the most reputable indexes (OKL, 2019). In this selection of information, the search was performed looking for the expression "internship report" in the Abstract or the Title.

To attain this goal, the preferred method for collecting information on the topic under study was document analysis, which was developed based on different types of documentary sources, with scientific articles being the main documentary source. The choice of the article as an empirical field of analysis results from considering that it is the key formal means of the scientific production and dissemination process. It is responsible for the scientific activity of scientists, whereas argumentative strategies of persuasion are developed and interpretative principles are favoured by authors and legitimated by peers.

After this stage, the documents resulting from this search were consulted and read in full. The selection of documents fell on those that directly articulated with the general framework in which the supervised internships, which substantiates certain principles of universal generic application.

\section{What is an Internship Report?}

The internship report is a document legally constituted as a document that reflects the work designed and implemented by the student in the context of a vocational internship. According to Assai et al. (2018) "the supervised internship is often part of higher education study programmes and one of its goals is to make the first contact of many students with the labour market. The internship is part of the student's training and the pedagogical project of some study programmes, including the specific ones of teacher training" (p. 2).

This report is the culmination of an internship process that encompasses three stages - the preparation of the internship, the completion of the internship and the reflection on this process translated into a product that tends to be written in the form of an internship report. What might be the purpose of an internship? (Parveen and Mirza, 2012) argue that

"A carefully planned internship program may have the following functions:

- Allow an understanding of the target profession and prospects of working conditions.

- Provide valuable job exposure.

- Develop professional skills and attitudes.

- Establish useful contacts with people working in the same profession” (p. 488).

Within this context, the internship report seeks to assess "activities that students have done during the internship; students' ability to reflect on the experience and integrate it with previous knowledge and skills. Thus, the internship report becomes an epistemic writing that determines growth of understanding and knowledge" (Salerni et al., 2013).

The internship report, like any scientific work, entails meeting several requirements: thinking activity, associated with knowledge activity, critical argumentation, scientific and ethical rigour, and coherence of theoretical and methodological options. A written work of a scientific nature presupposes a triple activity: questioning - going from social visibility to scientific visibility - conceptualisation - clarifying the meaning of the concepts and conceptual used - and argumentation. Argumentation, based on the questioning and conceptualisation components, aims to develop an argumentative strategy that critically organises the articulation of ideas, the path to follow and to oversee the possibility of the emergence of an ideological argumentation.

The internship report - being a written work of description, theoretical reflection and methodologically oriented (Akesson et al., 2018) towards the activities developed in the context of an internship carried out in organisations - should include the following components: description of the activities and their framing in the organisation where the internship was carried out; theoretical, methodological and technical-scientific underpinning of the activities developed; reflection and self-assessment of the work performed.

Following Fairchild (2010) there are essentially four ways to consider what an internship report is: an exposition of experiences - as information about what happened during the internship and a means for the supervisor to follow the activities and give the feedback deemed necessary; an accountability instrument - proving, through argumentation, the completion of the internship; an argumentative document - with the purpose of reasonably convincing the supervisor of the successful quality of the student's work during the internship; a work of organisation of an experience - that entails a very specific selection of various factors, such as what is relevant to mention and how to mention it on the part of the student, which "depends as much on the student's theoretical knowledge as on the image he/she has of the person whom he writes the text to" (Fairchild, 2010, p. 276).

But what is specifically expected an internship report to be?

Abdulai and Owusu-Ansah (2014) put forth their proposal in the form of dissertation or research thesis, considering that the work should contain a "research topic, research background and gap(s), research aim and objectives, research methodology, research significance/importance, research program, and references” (p. 3).

However, an internship report is different. Even looking at the context of teacher training, which seems to us that may be expanded, with the necessary specificities, to other situations of internship reports. Andrade and Martins (2017) maintain that "[ $[\ldots]$ the writing of the report has emerged as a space for understanding and restoration of a training path, highlighting important dimensions of professional knowledge built and to be built, where information activities such as the reading and analysis of pedagogical and didactic experiences, the dialogue with others and the reflection on the curriculum and the results of the experiences carried out are resumed to close a process whose development is thought to be continued" (p. 149). 


\section{The Process of Preparing an Internship Report}

The content and the organisation of an internship report is not always easy to define. This difficulty results from the combination of several factors, which, being occasionally convergent, create obstacles to the accomplishment of a work that is coherent and in line with the requirements of such a work.

On the one hand, we identify the student factor. Andrade and Mesquita (2016) highlight the insufficient mastery that students often have to address properly what is intended in an internship report. This constraint may, albeit even in an informal dimension, be coupled with an already established idea that goes from student to student about what an internship report is and how to prepare it Oliveira and Trivelato (2013).

On the other hand, it is also true that the internship report model differs greatly according to the specific scientific area, and these authors therefore recommend the need to specify the objectives very clearly to the students. Furthermore, it is necessary to consider the existence, which always occurs in practice, of some flexibility by both students and supervisors within the same training normative framework. Often, even within the same scientific area and within the same institution, internship reports are (too) different in structure and purposes (Melo et al., 2013; Silva, 2013). Sometimes, they may even, to some extent, be confused with a sheer description of the work carried out (Oliveira and Trivelato, 2013) or with the presentation of elements that are characteristic of a scientific research work tout court (Melo et al., 2013) which can undermine the student's confidence in his/her training.

Finally, we must not forget the supervisor and his/her role throughout the process. As Roberts and Seaman (2017) point out, "good supervision is essential in ensuring successful outcomes for undergraduate research students, yet to date few new supervisors have received training and support for this role, highlighting the importance of academic development in this area" (p. 38).

In any case, and starting with the negative elements, an internship report is not expected to:

- Be a description of the cooperating supervisor's work.

- Be an assessment of the cooperating supervisor.

- Be an exhaustive and uncritical description of the work carried out.

- Be a report of the work that could have been implemented.

- Be a set of theoretical citations with no explicit articulation with the justification and argumentation of the work developed.

The report is the culmination of a long process of articulating theory/practice/reflection. It is a whole that, as Mendonça (2017) states, "cannot be dissonant with the other disciplinary steps that make up the study programme because of the implications that emerge from the required articulation between the theoretical field, the ability for critical reflection and the practical action in the field of education" (p. 294). However, this experience of the internship and the preparation of the internship report is often not directly associated with the contents worked in the training or the existence of some difficulty in establishing this kind of relationship, resulting in a text that is "predominantly narrative and descriptive, informed, if anything, by diverse impressions" (Silva, 2013).

What is at stake is the necessary critical, intentional and grounded reflection that is the hallmark of the learning of the profession, which should be the starting point of the report and should lead its author to view the text not as a finished product but as a never-ending process of building the knowledge of the profession (Oliveira and Trivelato, 2013; Mendes et al., 2015).

As Melo et al. (2013) advocate, in the scope of the internship reports of the professionalising teacher training,

"In the internship reports, it is expected that the dialogues of the students-master established with other authors (other voices), with various theoretical approaches, are starting points for their fruitful reflections and the strengthening of their statements and conclusions, and they may contribute to orienting the critical view about the pedagogical practice experienced, in the context of formal instruction in basic education. The speeches cited cannot silence the voices of the students-master; otherwise, the function of reflective writing will be lost" (p. 106).

The internship report is, therefore, a process of professional knowledge construction, where theory and practice, know-how and interpretative knowledge dialogue with each other in the search to give an account of a particular training path, to give visibility to a project of professionalization and to foster social closure strategies developed by occupational groups, in which accreditation by the formal education system is critical (Rodrigues and Carvalho, 2004).

Given that it is a reflexive and unfinished process, the possibility of rewriting the internship report should be considered as a strategy that allows thinking about what has already been thought, a detachment from decisionmaking processes and their results. Mendes et al. (2015) when studying the process of (re)writing supervised internship reports in teacher training, even consider that it

"[...] adds to the development of the practice of reflection that should be part of the identity of the future mother tongue teacher. The results show, therefore, that rewriting should be a practice that is part of academic writing, adding to the strengthening of both academic literacy and the one needed for the workplace" (p. 510).

This results in the importance of clear indications of what is intended in a work of this nature. First and foremost, these indications should be known and clarified from the supervisors' viewpoint and, secondly, they should be transmitted to the students with accuracy, in the form of guidelines that allow students, as Parveen and Mirza (2012) point out, to "[...] act according to the rules and regulations as mentioned in the document" (p. 497).

Anyhow, and focusing on more specific aspects of the preparation of an internship report, there are common mistakes that should be prevented. Restrepo-Baena (2012) lists a number of them, which relate to formal aspects and the content itself. Some examples of these mistakes are the inability to synthesise, the lack of clarity, the lack of order in the planning of ideas, repetitions, grammatical errors, spelling and punctuation typos, plagiarism, voluntary or otherwise, inaccuracies in referencing, the use of words that do not exist, the excessive use of graphs, tables or figures, literal translations and the lack of agreement on gender and number, among many others.

Restrepo-Baena (2012) highlights an important aspect of the report's writing and rewriting process - the absence of self-critical correction. During the report's writing, the trainee is unlikely to be available, due to lack of time and critical detachment and accumulated tiredness, to detect errors (in content and form). As the author 
points out, the brain refuses to see new things that an external and impartial reader easily detects, so he advises to "let the text cool" for a while, to look at it in a more detached and critical way in a later reading.

And because we live in the digital era, an internship report must, currently, also reflect new forms of writing. As Gatenby (2018) states, "Technology has made traditional models of teaching writing obsolete [...] The ability to convey information in short, direct bursts of writing is now the standard model of communication, not the ability to write long, complex sentences in fully developed paragraphs. Until writing programs accept and focus on this fundamental change in the worlds of information and education, they will continue their downward slide into educational irrelevance" (p. 72).

Whatever the case may be, at the end of the process there is a set of issues that should be raised by supervisors as a way to regulate the quality of the process and product. These issues are related, on the one hand, to the internal articulation between the different elements of the report (starting question, title, abstract, data presented, conclusions) and their necessary coherence and, on the other hand, with the preparation of the text itself. The set of issues raised by the supervisor and addressed by the student help enhancing the process and reflecting the quality of all the work undertaken (well-expressed ideas, a well-grounded critical reflection, and the scientific and academic quality of the ideas mobilised) (Restrepo-Baena, 2012).

Finally, and given that this process of constructing an internship report is an individual process, we totally agree with Duffy et al. (2018) when the authors argue that

"Our field has a grand opportunity to identify new topics and dimensions to explore through research. Establishing an expectation of students that their thesis or dissertation topic will not be a replication or the continuation of the same old, same old, then empowering them to explore new ideas will provide for a richer more dynamic experience for student and professors while enriching and diversifying our literature” (p. 86).

\section{Conclusions}

The structure of an internship report has a set of core elements that must be taken into account in its preparation. Firstly, it should include an introduction, which puts forth the reasons for the choice and importance of the topic, the objectives, a brief description of the organisation where the internship was carried out, a brief presentation of the theoretical and methodological option followed, as well as a brief presentation of the report's chapters. Another central element are the theoretical and methodological underpinnings, which set out the theoretical perspective adopted to frame the description of the organisation, the context and the activities developed in the internship and the presentation and discussion of the methodological options, namely, the research strategy, methods, observation instruments and data collection and treatment procedures. At this point of the report, it is important to develop the theoretical problematization of the work and the professional-technical knowledge that frames the reflection on the trainee's professional role, discussing, namely, the concepts of profession, professionalism, professional culture, intellectual-professional work -design, organisation, planning of the production of goods or services, social relationship between professionalism and decision, technical action in the professional use of knowledge or social reflexivity (Caria, 2005). The characterisation of the organisation and the context in which the internship takes place and the presentation and analysis of the activities are two relevant elements. The reflection on the professional role of the trainee is a decisive element, albeit often overlooked. This reflection is guided by the discussion of theoretical versus workplace training and encompasses the theoreticalmethodological, interpersonal and organisational skills, as well as the distinctive skills - demonstration of the advantages and contributions of the trainee's theoretical and technical knowledge for the accomplishment of the various activities and subsequent visibility of the academic and professional project of the study programme. The last textual element is the conclusion, where the objectives are resumed and the extent to which these objectives have been attained is put forward. The trainee has the possibility, thus, of pointing out the positive and negative aspects that emerged from the internship, taking into account the various types of knowledge and skills attained during the curricular training. Post-textual elements -references, annexes and appendices - are yet another critical element of the internship report.

As expressed throughout this paper, the construction of an internship report is a long and somewhat lengthy process, beginning many years before the internship itself and involving the mobilisation of theoretical, methodological, experiential, personal, and perhaps technical frameworks from those who experience the process itself. During this path, several obstacles, both internal and external, emerge. However, various strategies can be used to ensure an effective and efficient work path that ensures the quality of the scientifically grounded reflection that is sought to be an indelible mark of this type of academic work.

In this sense, we endorse the words by Duffy et al. (2018) when the authors posit that " [...] professors should have no qualms about encouraging students to learn and implement these strategies regardless of the career goals of incoming students. The processes [...] are more complex than simply instructing students to read the literature and figure out a way to extend it. With less emphasis on extending a research literature, and more on developing new areas of research by considering diverse information sources and the process of thinking, both the quality of our students' preparation and the credibility of our field will increase” (p. 86).

\section{References}

Abdulai, R.T. and A. Owusu-Ansah, 2014. Essential ingredients of a good research proposal for undergraduate and postgraduate students in the social sciences. Sage Open, 4(3): 2158244014548178 .Available at: https://doi.org/10.1177/2158244014548178.

Akesson, B., M. Braganza and J. Root, 2018. Is theory development essential for the social work dissertation? Social Work Education, $37(2)$ : 209-222.Available at: https://doi.org/10.1080/02615479.2017.1391196.

Andrade, A.I. and F. Martins, 2017. Challenges and possibilities in teacher education - around internship report analysis. Educate in Review, 33(63): 137-154

Andrade, V. and E. Mesquita, 2016. The introduction of the supervised internship report: A rhetorical analysis. Lingu@gem Domains, $10(1): 68-88$.

Assai, N.D.S., F.C.D. Broietti and S.M. Arruda, 2018. Supervised internship in initial teacher education: State of the art of national science research [supervised internship in teacher training]. Education in Review, 34(1): 1-44.

Badger, J., 2012. Analyzing levels of feedback delivered by cooperating teachers and supervisors in a teacher internship: A case study. Georgia Educational Researcher, 9(1): 21-39.Available at: https://doi.org/10.20429/ger.2012.090102. 
Braga, J., 2015. Supervised internship in the teacher training program: Tensions and reflections. Electronic Journal of Education, 9(1): 251261.Available at: https://doi.org/10.14244/198271991073.

Caria, T., 2005. Saber profissional [professional knowledge]. Coimbra: Almedina Editions.

Ciučiulkienè, N. and R. Mičiuliené, 2019. Mentoring styles and their contribution to pedagogical and didactic competence development. Society. In Integration. Education. Proceedings of the International Scientific Conference. 1, pp: 131-143.

Duffy, L.N., H.P. Pinckney IV, G.M. Powell, R.D. Bixler and F.A. McGuire, 2018. Great theses and dissertation start with an intriguing idea. Journal of Hospitality, Leisure, Sport \& Tourism Education, 22: 82-87.Available at: https://doi.org/10.1016/j.jhlste.2018.03.001.

Ellis, V. and A. Childs, 2019. Innovation in teacher education: Collective creativity in the development of a teacher education internship. Teaching and Teacher Education: An International Journal of Research and Studies, 77(1): 277-286.Available at: https://doi.org/10.1016/j.tate.2018.10.020.

Fairchild, T., 2010. The teacher in the mirror: Reflecting on reading an internship report in undergraduate letters. Brazilian Journal of Applied Linguistics, 10(1): 271-288.Available at: https://doi.org/10.1590/s1984-63982010000100014.

Gabassa, V., C.R. Elias and V.C. Girotto, 2017. The non-conventional internship and its contributions to teachers' education and training. Educational Magazine, 2O(2): 408-430.Available at: https://doi.org/10.18224/educ.v20i2.6242.

Gatenby, B.M., 2018. Teaching writing without academic writing: Transitioning from aristotle to the twitter world. International Journal of Language and Linguistics, 5(3): 72-74.Available at: https://doi.org/10.30845/ijll.v5n3p7.

Gomes, O.d.M. and d.M.L. Santana, 2019. The teaching profession and the praxis of Geography Teaching: reflections from the supervised internship in a public school in Delmiro Gouveia / AL. Diversitas Journal, 4(2): 480-495.Available at: https://doi.org/10.17648/diversitas-journal-v4i2.800.

Lima, d.A.V., M.F. Milleto and J.V.L. Robaina, 2018. Challenges and potentialities of the supervised internship of the interdisciplinary course in education of the natural sciences field. Tear: Journal of Education, Science and Technology, 7(2): 1-10.Available at: https://doi.org/10.35819/tear.v7.n2.a3195.

Lopes, B., P. Silva, A.I. Melo, E. Brito, G.P. Dias and M. Costa, 2019. The 'lunar side'of the story: Exploring the sustainability of curricular internships in higher education. Sustainability, $11(21): 1-22$.

Mattos, L.J.G. and d.S.C. Santos, 2018. The challenges of the supervised internship in a distance degree course. ODL in Focus, 8(1): 110.Available at: https://doi.org/10.18264/eadf.v8i1.643.

Melo, d.L.C., A.V. Gonçalves and W.R. Silva, 2013. Academic writing in professional reflective writing: Citations of scientific literature in supervised internship reports. Bakhtinian. Discourse Studies Journal, 8(1): 95-119/Eng. 194-117.Available at: https://doi.org/10.1590/s2 176-45732013000100007.

Mendes, A.S., W.R. Silva, A.V. Gonçalves and L.C. Melo, 2015. Intensification of reflection in teacher writing in initial education: A systemic-functional approach. Filology and Portuguese Linguistics, 17(2): 509-537.Available at: https://doi.org/10.11606/issn.2176-9419.v17i2p509-537.

Mendonça, F.D.d.L.R., 2017. Supervised internship report: Constitutive discursive pedagogical practice of initial teacher education in the letters course. Raido, 11(27): 292-303.Available at: https://doi.org/10.30612/raido.v1 1i27.5681.

Nisly, S., L. Brennan, L. Verbosky, A. Raymond and J. Tryon, 2018. Creating a pharmacy internship: A toolbox for success. INNOVATIONS in Pharmacy, 9(4): 11-11.Available at: https://doi.org/10.24926/iip.v9i4.1394.

Oliveira, O.B.d. and S.L.F. Trivelato, 2013. On textual genres used in Biology teacher trainning development. DELTA: Documentation of Studies in Theoretical and Applied Linguistics, 29(2): 341-361.

Online Knowledge Library, 2019. Quem somos [who we are]. Available from https://www.b-on.pt/quem-somos/ [Accessed September 3, 2019].

Parveen, S. and N. Mirza, 2012. Internship program in education: Effectiveness, problems and prospects. International Journal of Learning \& Development, 2(1): 487-498.Available at: https://doi.org/10.5296/ijld.v2i1.1471.

Restrepo-Baena, E.A.R., 2012. Common mistakes in the development of scientific articles. CES Medicina, 26(1): 131-134.

Roberts, L.D. and K. Seaman, 2017. Good undergraduate dissertation supervision: Perspectives of supervisors and dissertation coordinators. International Journal for Academic Development, 23(1): 28-40.Available at: https://doi.org/10.1080/1360144X.2017.1412971.

Rodrigues, M. and H. Carvalho, 2004. Between public and private - Professional associations in Portugal. In J. Freire (Org.), Professional Associations in Portugal. Oeiras: Celta Publisher. pp: 257-298.

Salerni, A., P. Sposetti and G. Szpunar, 2013. Written narration as an element of evaluation of the university internship. Pedagogy and Didactic Research. Journal of Theories and Research in Education, 8(2): 9-26.

Silva, W.R., 2012. Proposal for textual-discursive analysis of the supervised internship report [proposal of textual-discursive analysis of the supervised internship report]. D.E.L.T.A, 28(2): 281-305.

Silva, W.R., 2012;2013. Proposal for textual-discursive analysis of the supervised internship report [proposal of textual-discursive analysis of the supervised internship report]. D.E.L.T.A, 28(2): 281-305.

Silva, W.R., 2013. Writing of the genre supervised internship report in the initial formation of the Brazilian teacher. Brazilian Journal of Applied Linguistics, 13(1): 171-195.Available at: https://doi.org/10.1590/s1984-63982012005000016.

Tiessen, R., 2018. Improving student reflection in experiential learning reports in post-secondary institutions. Journal of Education and Learning, 7(3): 1-10. 